\title{
Chronic pulmonary histoplasmosis in Portugal: a case report
}

\author{
João Parreira, Madalena Reis, José Silva, Luís Ferreira \\ Serviço de Pneumologia; Unidade Local de Saúde da Guarda, EPE; Guarda, Portugal
}

\begin{abstract}
Pulmonary histoplasmosis is a rare disease in Europe caused by Histoplasma capsulatum, a dimorphic fungus present in the soil contaminated with excrements of birds and bats. There are two varieties, variety capsulatum endemic of American continent and variety duboisii endemic of African continent. All cases in Europe were imported. In this article, we present a case of chronic pulmonary histoplasmosis, a rare presentation of histoplasmosis in an immunocompetent man several years after he has lived in a endemic region of Africa. He complained of fatigue and dyspnea in the last two years. In computed tomography of the chest, it was verified multiple and bilateral focus of densification with peribronchovascular distribution. Transthoracic lung biopsy was then requested, whose pathological anatomy revealed epithelioid granulomas infected by yeast from Histoplasma capsulatum.

Palabras clave: Histoplasma capsulatum. Histoplasmosis pulmonar. Histoplasmosis pulmonar crónica.

Keywords: Histoplasma capsulatum. Pulmonary histoplasmosis. Chronic pulmonary histoplasmosis-
\end{abstract}

\section{Introduction}

Pulmonary histoplasmosis is a rare disease in Europe ${ }^{1}$, caused by Histoplasma capsulatum, a dimorphic fungus. It has two varieties (var.), Histoplasma capsulatum var. capsulatum endemic of American Continent and Histoplasma capsulatum var. duboisii endemic of African Continent?

The var. capsulatum has as its natural reservoir the soil contaminated by bat or bird droppings ${ }^{2}$. The infection occurs by the inhalation of spores of contaminated places, however, it does not always lead to the development of the disease since the most cases are asymptomatic or have only mild symptoms ${ }^{3}$. The most serious forms of disease are rare in immunocompetent, but are serious in immunosuppressed patients, mainly those infected by the virus of acquired human immunodeficiency3.

The var. duboisii has as its natural reservoir the soil and its mode of transmission is less known ${ }^{4}$. It is thought to occur directly through trauma, leading to skin, soft tissue or bone infections ${ }^{5}$. Rarely, dissemination occurs and the latency period is prolonged ${ }^{6}$. Some cases of illness are described many years after exposure ${ }^{7}$, especially in patients who have been in the military or who have lived/worked in endemic areas.

The disease may assume three major forms ${ }^{8}$, namely acute pulmonary histoplasmosis, chronic pulmonary histoplasmosis and progressive disseminated histoplasmosis.

In this article, the authors describe a case of chronic pulmonary histoplasmosis in a Portuguese man, more than $\mathbf{4 0}$ years after having lived in an endemic zone in Africa.

\section{Case Report}

A 73-year-old Caucasian man was admitted to the Pneumology Service in March 2013 from the outpatient clinic of Pulmonology for aggravation of exertional dyspnea and marked weight loss, namely $10 \mathrm{~kg}$ in the last 5 months. He was a non-smoker, born in Lisbon, retired from welder and resident in Guarda. Of the personal antecedents, he had typhoid fever at 7 years old, malaria at 27 years old, sequelae of upper limb trauma, non-insulin dependent type 2 diabetes mellitus, hypertension, dyslipidemia and benign prostatic hyperplasia. Usually medicated with metformin, losartan/ hydrochlorothiazide, simvastatin, omeprazole and finasteride. He reported regular contact with chickens and past contact with pigeons and bats in the 10 years that he lived in Guinea-Bissau. He complained of fatigue and dyspnea (modified Medical Research Council grade 4) with about 2 years of evolution and had performed several exams but not conclusive. He was eupneic at rest with 02 saturation of $90 \%$, afebrile, emaciated aspect, without palpable adenopathies. Pulmonary auscultation with disperse crepitations in both lung fields and rhythmic cardiac auscultation, with degree III / VI holosystolic murmur.

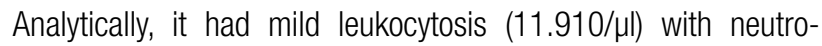
philia of $84.4 \%$, hemoglobin of $12.5 \mathrm{~g} / \mathrm{dl}$, glucose of $132 \mathrm{mg} / \mathrm{dl}$, sedimentation rate of $94 \mathrm{~mm} / \mathrm{h}$, C-reactive protein of $5.30 \mathrm{mg} / \mathrm{dl}$, autoimmunity with anti-mitochondrial antibodies on the order of $160(\mathrm{~N}<80)$ with the remaining study negative. Serologies for HIV 1 and 2 were negative. The chest radiograph showed a bilateral reticular pattern and pseudo-nodular infiltrates at the upper third of both lung fields and the lower right third.

The pulmonary function tests revealed mixed ventilatory syndrome with FEV1 of $62 \%$ and TLC of $75 \%$ (Table 1). The arterial blood gas analyses revealed partial respiratory failure with $\mathrm{PaO} 2$ of $54.1 \mathrm{mmHg}$.

Computed tomography of the chest showed bilateral traction bronchiectasis at the level of the lower lobes. Thickening of the bronchial walls and densification of the bronchovascular sheaths bilaterally associated with multiple foci of densification with bilateral peribroncovascular distribution. There was mediastinal ganglia at the aorto-pulmonary window with a maximum diameter of 12 $\mathrm{mm}$. Common pulmonary artery trunk with $34 \mathrm{~mm}$ and presence of cardiomegaly (Figure 1). 
Table 1. Pulmonary function tests

\begin{tabular}{|l|c|c|c|c|c|c|}
\hline & Ref & Pre meas & Pre/Ref (\%) & Post meas & Post/Ref (\%) & Chg \\
\hline FVC (L) & 3.54 & 2.56 & 72 & 2.59 & 73 & 1 \\
\hline FEV1 (L) & 2.70 & 1.67 & 62 & 1.71 & 63 & 2 \\
\hline FEV1/FVC (\%) & 74 & 65 & & 66 & & \\
\hline FEF 75/25 (L/s) & 2.86 & 0.85 & 30 & 0.92 & 32 & 7 \\
\hline TLC (L) & 2.61 & 4.86 & 75 & & & \\
\hline RV (L) & 2.60 & 2.18 & 84 & & & \\
\hline RV/TLC (\%) & 42 & 45 & 107 & & & \\
\hline
\end{tabular}

Bronchofibroscopy revealed signs of extrinsic compression at the right lateral wall of the trachea and distortion of the right basal pyramid with slit bronchi. The bronchial aspirate revealed commensal flora, with direct, cultural examination and DNA research negative for Mycobacterium tuberculosis. The cytology of the aspirate showed little inflammatory infiltrate, without necrosis, giant cells and/or neoplastic cells.

To exclude neoplastic disease, the patient underwent mediastinoscopy, whose histology of the mediastinal ganglia revealed maintenance of the usual morphology with lymphoid follicles with active germinative centers and retention of anthracosis pigments, therefore, without relevant alterations. Subsequently, the patient was then sent for surgical lung biopsy, performed on the upper and lower right lobe. Histology demonstrated inflammatory tissue replacing the pulmonary parenchyma, consisting of fibroblast proliferation with lymphoplasmacytic overlap and lymphoid tissue hyperplasia, with dispersed epithelioid granulomas whose Langhans-type multinucleated giant cells contain rounded fungal structures in the cytoplasm, identified by Periodic Acid-Schiff that demonstrate double wall. Focally there are neutrophilic microabcesses. Pulmonary nodules were scattered throughout the pulmonary parenchyma, with a subpleural localization and adjacent Iymphatic ganglion formation, with epithelioid granulomas infected by fungal structures with morphology compatible with histoplasma capsulatum (Figure 2).

Although it was not possible to identify the histoplasma variety, it was presumed to be the duboisii variety, considering the residence in an endemic zone in Africa.

The patient started itraconazole 200mg bid in May 2013, with progressive clinical improvement, with treatment discontinued after completing 10 months of treatment because of gastric intolerance.

Figure 1. Computed tomography showing multiple densification foci with bilateral peribroncovascular distribution (arrows) and traction bronchiectasis in the lower lobes (arrowheads).

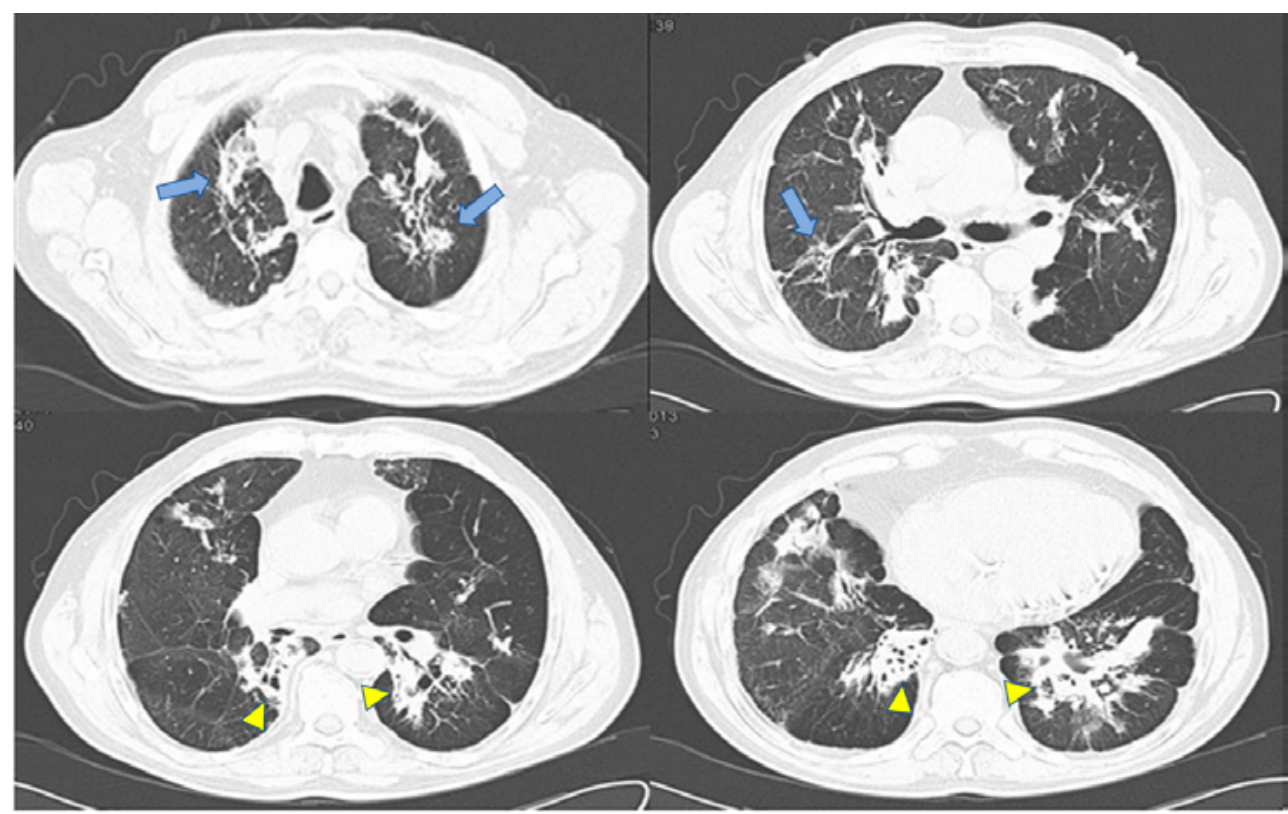




\section{Discussion}

Pulmonary histoplasmosis is a rare disease in Portugal, with cases identified related to travel and/or residence in endemic areas. In this case there was a long latency period, which made diagnosis even more difficult, requiring a complete history of the places where the patient traveled and/ or resided. Considering the characteristics of the lesions, the differential diagnosis with pulmonary tuberculosis and neoplastic/lymphoproliferative disease is recommended in these cases.

Regarding treatment, there are no specific guidelines for the treatment of Histoplasma capsulatum var. duboisii infection, being the treatment based on the recommendations for Histoplasma capsulatum var. capsulatum. Given the limited number of cases described in the literature, more data are needed on epidemiology and especially on its evolution and effective treatment.

\section{Bibliography}

1. Nyffenegger L, Abbas M, Gex G, Boffi E, Schrenzel J, Bouchuiguir-Wafa K, Hirschel B.; Imported cases of histoplasmosis; Rev Med Suisse. 2009 Nov 25; 5(227):2418-23.

2. Bonifaz A, Vázquez-González D, Perusquía-Ortiz AM. Endemic systemic mycoses: coccidioidomycosis, histoplasmosis, paracoccidioidomycosis and blastomycosis. $J$ Dtsch Dermatol Ges. 2011; 9(9):705-14.

3. Kauffman CA. Histoplasmosis: a clinical and laboratory update. Clin Microbiol Rev. 2007;20(1):115-32. Review. www.ncbi.nlm.nih.gov/pmc/articles/PMC1797635/

4. Loulergue $P$, Bastides $F$, Baudouin V, et al. Literature review and case histories of Histoplasma capsulatum var. duboisii infections in HIV-infected patients. Emerg Infect Dis. 2007 Nov;13(11):1647-52. www.ncbi.nlm.nih.gov/pmc/articles/ PMC3375808/

5. Antinori S. Histoplasma capsulatum: more widespread than previously thought. Am J Trop Med Hyg. 2014;90(6):982-3. www.ncbi.nlm.nih.gov/pmc/articles/ PMC4047757/

6. R. Sabino, C. Verissímo, J. Brandão, C. Martins, D. Alves, C. Pais et D. W. Denning Serious fungal infections in Portugal, Eur J Clin Microbiol Infect Dis, December 2016.

7. Toscano V, Batista J, Carvalho R, et al. Imported african histoplasmosis by Histoplasma capsulatum var. duboisii in an HIV-2 infected patient. 6th Trends in Medical Mycology, Copenhaga, 2013. Poster. http://repositorio.insa.pt//handle/10400.18/1813.

8. Akram SM, Koirala J. Histoplasmosis. [Updated 2017 Oct 9]. In: StatPearls [Internet]. Treasure Island (FL): StatPearls Publishing; 2018 Jan-. Available from: https:// www.ncbi.nlm.nih.gov/books/NBK448185/.

Figure 2. Pulmonary biopsy showing Histoplasma capsulatum yeasts (arrows), H\&E stain, courtesy of the Service of Pathological Anatomy of Centro Hospitalar e Universitário de Coimbra

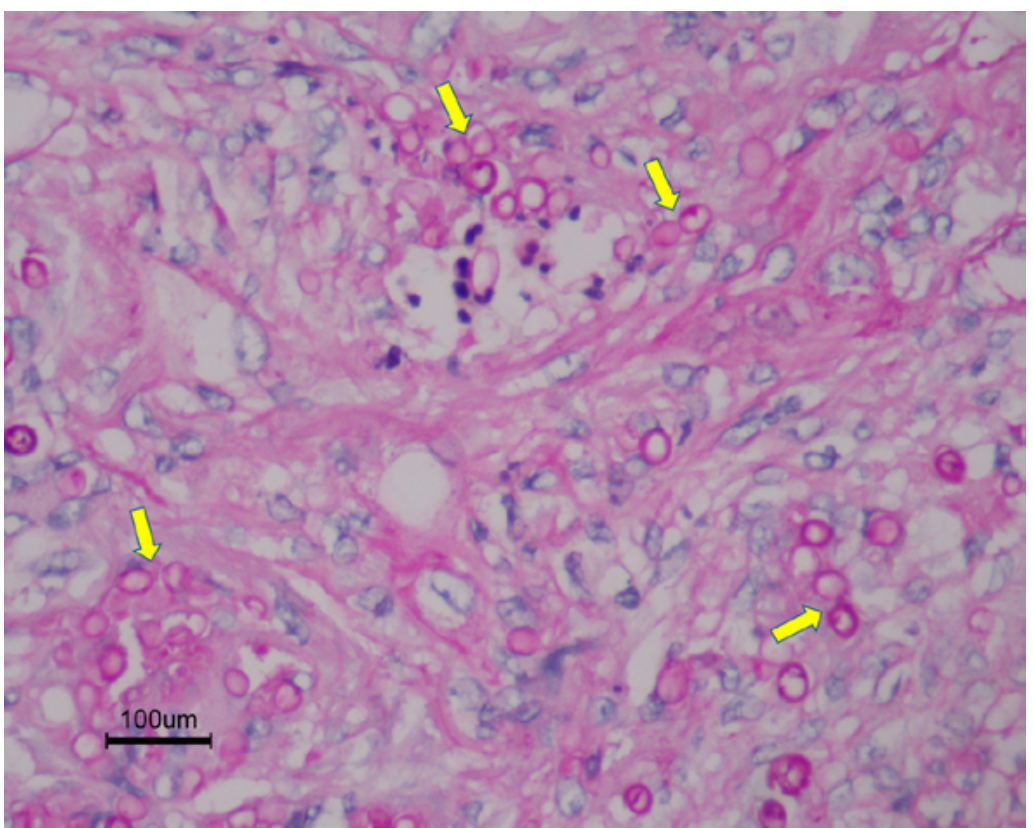

